\title{
BENTUK-BENTUK HONORIFIK DALAM BERBAHASA CIACIA
}

\author{
Ahmadin', La Ode Sidu Marafad ${ }^{2}$ dan Sulfiah $^{3}$ \\ pbsi.fkip.uho@gmail.com \\ 1,2,3, Jurusan Pendidikan Bahasa dan Sastra Indonesia, \\ Fakultas Keguruan dan Ilmu Pendidikan, Universitas Halu Oleo \\ Kampus Hijau Bumi Tridharma Anduonohu, Kendari, Indonesia
}

\begin{abstract}
ABSTRAK
Tujuan yang ingin dicapai dari penelitian ini adalah untuk mendeskripsikan Bentukbentuk ungkapan honorifik pada masyarakat Desa Gunung Sejuk. Penelitian ini menggunakan metode deskriptif kualitatif bertujuan untuk mengungkap sebuah fakta empiris secara objektif ilmiah dengan berlandaskan pada logika keilmuan, prosedur dan didukung oleh metodologi dan teoritis yang kuat sesuai disiplin keilmuan yang ditekuni. Teknik pengumpulan data dalam penelitian ini dilakukan dengan Metode Observasi, Teknik pengumpulan data dengan mengadakan pengamatan secara lansung terhadap masyarakat Gunung Sejuk untuk menemukan bentuk-bentuk ungkapan honorifik dalam berbahasa yang digunakan oleh masyarakat Desa Gunung Sejuk, dalam teknik observasi ini peneliti menggunakan dua jenis observasi yaitu, observasi bebas dan observasi terencana. Teknik kerja sama dengan informan teknik memperoleh data dengan bekerja sama dengan informan mengenai bentuk-bentuk ungkapan honorifik dalam berbahasa Ciacia, teknik simak dan catat yaitu mencatat keseluruhan data yang diperoleh dari informan. teknik rekam yaitu teknik yang digunakan untuk merekam pembicaraan informan di lingkungan masyarakat Desa Gunung Sejuk. Dari hasil penelitian yang dilakukan mengenai Analisis Bentuk-bentuk Honorifik dalam Berbahasa Ciacia. Maka penulis dapat menyimpulkan bahwa masyarakat Desa Gunung Sejuk menggunakan bentuk-bentuk honorifik dalam berkomunikasi. Bentuk-bentuk honorifik tersebut dikategorikan dalam lima jenis honorifik yaitu, honorifik kekerabatan, honorifik pronomina persona, honorifik gelar, honorifik jabatan dan honorifik profesi. Penggunaan bentuk-bentuk honorifik tersebut digunakan dalam proses komunikasi pada masyarakat Desa Gunung Sejuk berdasarkan tingkat kedudukan sosial dalam masyarakat.
\end{abstract}

Kata kunci : Bentuk; Bahasa Ciacia; Honorifik,

165 I Jurnal BASTRA (BahasadanSastra), Vol. 5 No.2, Edisi April 2020/e-ISSN: 25033875 /http://ojs.ohu.ac.id/index.php/BAS 


\begin{abstract}
The aim of this research is to describe the forms of honorific expressions in the community of GunungSejuk Village. This study uses descriptive qualitative method aimed at revealing an empirical fact objectively scientifically based on scientific logic, procedures and supported by strong methodology and theoretical according to the scientific discipline that is pursued. Data collection techniques in this study were carried out by Observation Method, Data collection techniques by conducting direct observations of GunungSejuk people to find forms of language honorific expressions used by the people of GunungSejuk Village, in this observation technique researchers used two types of observations namely, free observation and planned observation. The technique of cooperating with technical informants obtains data by working with informants about the forms of honorific expressions in Ciacia language, the technique of referring and noting is recording all the data obtained from the informant. recording technique is a technique used to record the conversation of informants in the community of GunungSejuk Village. From the results of research conducted on the Analysis of Honorific Forms in the Language of Ciacia. So the author can conclude that the people of GunungSejuk Village use honorific forms of communication. The honorific forms are categorized into five types of honorifics, namely, kinship honorifics, honorific personal pronouns, title honorifics, position honorifics and professional honorifics. The use of honorific forms is used in the communication process in the community of GunungSejuk Village based on the level of social position in the community.
\end{abstract}

\title{
Keywords: CiaciaLanguage; Honorific; Shape
}

166 Jurnal BASTRA (BahasadanSastra), Vol. 5 No.2, Edisi April 2020/e-ISSN: 25033875 /http://ojs.ohu.ac.id/index.php/BAS 


\section{PENDAHULUAN}

\section{Latar Belakang}

Bahasa sebagai sarana komunikasi memegang peran yang sangat penting bagi masyarakat dalam lingkungan sosial. Peran penting bahasa dapat dibuktikan dengan adanya bahasa komunikasi antar kelompok masyarakat dalam kehidupan sosial dapat berjalan dengan baik. Dengan bahasa pula, seorang individu dapat mengungkapkan segala ide dan gagasan yang ada dalam pikirannya sesuai maksud dan tujuannya.

Bahasa juga merupakan unsur dan sarana pengungkap kebudayaan, pelestarian kebudayaan, serta identivikasi budaya bagi suatu kelompok masyarakat. Fungsi penting bahasa inilah yang menjadikan bahasa sebagai unsur kebudayaan nomor satu bagai setiap suku bangasa maupun kelompok manusia

Bahasa sebagai alat komunikasi yang terususun secara sistematis tentu memiliki struktur yang mengatur bahasa itu sendiri, hal ini menunjukan bahwa bahasa bukanlah merupakan suatu sistem tunggal yang tidak memiliki susunan struktur atau subsistem yang jelas. Setiap unsur yang membangun bahasa dibuat dan disepakati oleh masyarakat dari pengguna bahasa tertentu, hal ini sejalan dengan yang di kemukakan oleh Kridalaksana (dalam Chaer 2007: 32) bahasa adalah sistem lambang bunyi yang arbitrer yang digunakan oleh para anggota kelompok sosial untuk bekerja sama, berkomunikasi, dan mengidentifikasi diri. Hal ini menunjukan bahwa funsi dan subsistem dan struktur bahasa dalam masyarakat adalah hasil dari kesepakatan oleh anggota kelompok masyarakat tersebut yang berfungsi sebagai sarana untuk berkomunikasi, berinteraksi, dan mengidentifikasi diri.Setiap bangsa mempunyai bahasa masing-masing, seperti halnya dengan bangsa Indonesia yang mempunyai bahasa sendiri yaitu bahasa Indonesia.

Bahasa Indonesia adalah bahasa yang digunakan secara Nasional di Negara Kesatuan Republik Indonesia dan berfungsi sebagai alat pemersatu Bangsa.Bangsa Indonesia adalah bangsa yang multilingual yang tersebar dari Sabang sampai Merauke. Hal ini tentunya membuat warga Negara Indonesia pada umumnya paling sedikit menggunakan dua bahasa yaitu bahasa daerah atau bahasa Ibu dan bahasa Indonesia pada saat melakukan komunikasi dalam kehidupan seharihari. Bahasa daerah dipakai untuk keperluan komunikasi antarwarga dalam suku, sedangkan kegiatan komunikasi antarsuku digunakan bahasa Indonesia.Setiap suku tentu memiliki kebudayaan dan bahasa yang berbeda antara satu dengan yang lainnya, salah satunya adalah bahasa Ciacia.

Bahasa Ciacia adalah salah satu dari sekian banyaknya bahasa daerah yang ada di Nusantara yang masih dipertahankan oleh masyarakat penggunanya, salah satu pengguna bahasa Ciacia adalah masyarakat Buton Selatan yang berada di Desa Gunung 
Sejuk. Kelestarian bahasa daerah yang ada di Indonesia termaksud di dalamnya bahasa Ciacia dijamin oleh Undang-undang Dasar 1945 “Di daerah yang mempunyai bahasa sendiri yang dipelihara oleh rakyatnya dengan baikbaik (bahasa jawa, sunda, madura. dan sebagainya) bahasa-bahasa itu dihormati dan dipelihara oleh negara. Bahasa itupun merupakan sebagian dari kebudayaan manusia yang hidup". Bahasa Ciacia merupakan salah satu bahasa daerah yang ada di Sulawesi Tenggara yang diharapkan dapat memberikan sumbangan dalam pengembangan dan pembinaan bahasa nasional.

Bahasa Ciacia dalam kedudukannya sebagai bahasa daerah yang sejajar dengan bahasa daerah lainnya yang ada di Indonesia mempunyai peranan dan fungsi yang cukup besar di kalangan masyarakat pendukungnya. Selain digunakan sebagai sarana komunikasi dalam peergaulan sehari-hari, bahasa Ciacia juga digunakan sebagai sarana komunikasi dalam kegiatan kemasyarakatan seperti upacara adat, upacara lamaran, kegiatan kebudayaan, dan keagamaan. Hal tersebut menunjukan bahwa pentingnya bahasa Ciacia dalam kehidupan masyarakat penuturnya, sehingga perlu adanya upaya pembinaan dan pengkajian bahasa daerah guna meningkatkan mutu pemakaian dan memperkaya perbendaharaan bahasa Indonesia serta khasanah kebudayaan nasional.
Dalam upaya mempertahankan kelestarian bahasa Ciacia, dan upaya meningkatkan kualitas komunikasi agar tercipta komunikasi yang baik antar sesama penutur bahasa Ciacia, maka perlu adanya pengkajian terhadap Penggunaan honorifik dalam berbahasa Ciacia pada masyarakat Gunung Sejuk.salahsatucontohpenggunaaanhon orifik antara lain sebagai berikut:

Konteks : peristiwa komunikasi terjadi atara cucu dan kakek

Cucu : Ompu, maimo ta ma'a aso.

( Nek, ayo kita makan )

Nenek : Umbe, papangulu siemo отри-отри'u

(Iya, duluan saja cucuku )

Kata ompu pada kalimat di atas menunjukkan salah satu bentuk sapaan honorifik yang digunakan oleh sang cucu terhadap neneknya, yaitu dengan menggunakan panggilan ompu, bukan dengan memanggil nama, karena panggilan nama terhadap orang yang lebih tua dianggap tidak santun dalam berbahasa

Penggunaan honorifik dalam berbahasa di kalangan masyarakat sangatlah penting guna menjaga agar terjadinya komunikasi yang baik. Memang tidak ada yang berhak melarang, menyalahkan dan mengatur seseorang mengungkapkan sebuah tuturan dalam berbahasa. Namun perlu dicatat bahwa bangsa Indonesia kental dengan budaya sopan santun budaya bertutur dan yang demikian merupakan 
sifat alamiah setiap suku bangsa di Indonesia termaksud bahasa Ciacia. Dalam upaya bagaimana mengajak kembali penutur-penutur tersebut atau memeperhatikan penggunaan ungkapan kesopanan dalam bahasa Ciacia, maka peneliti merasa perlu untuk mengadakan penelitian, sebagai wujud kecintaan terhadap bahasa Ciacia dalam upaya peningkatan dan pemertahanan mutu dan fungsi bahasa Ciacia itu sendiri.

Penelitian ini mengkaji tentang penggunaan honorifik atau kesantunan dalam berbahasa yang dilakukan oleh masyarakat yang ada di Desa Gunung Sejuk, Kecamatan Sampolawa Kabupeten Buton Selatan dalam menggunakan bahasa Ciacia, peneliti menggunakan istilah honorifik dalam penelitian ini bertujuan memberikan tambahan pemahaman dalam upaya memperkaya pengetahuan tentang bentuk-bentuk dari honorifik dalam bahasa Ciacia, selain itu pula karena istilah honorifik belum banyak gunakan oleh peneliti-peneliti sebelumnyakhususnyapadapenelitiante ntangbahasaCiacia.

Rumusan MasalahMengacu pada latar belakang di atas, maka permasalahan dalam penelitian ini adalah "Bagaimanakah Bentuk-Bentuk Honorifik dalam Berbahasa Ciacia?".

Tujuan PenelitianTujuan yang ingin dicapai dalam penelitian ini adalah "Mendeskripsikan BentukBentuk Honorifik atau Ungkapan
Kesopan Santunanan dalam Berbahasa Ciacia".

\section{Manfaat Penelitian}

Penelitian ini diharapkan mampu meberikan sumbangan untuk pengembangan tentang teori-teori pragmatik dalam penelitian selanjutnya, serta perbaharuan tentang kesantunan berbahasa dan pengembangan ilmu bahasa, adapun manfaat lain dari penelitian ini adalah.

1. Sebagai bahan masukan kepada masyarakat tentang bentuk-bentuk honorifik dalam bahasa Ciacia.

2. Sebagai bahan rujukan atau perbandingan untuk penelitian selanjutnya yang relevan dengan penelitian ini.

Penelitain ini menggunakan metode deskriptif kualitatif, digunakan metode kualitatif karena dalam penelitian ini hanya mendeskripsikan tentang bentuk-bentuk honorifik dalam berbahasa Ciacia dalam masyarakat Desa Gunung Sejuk.

Jenis penelitian ini adalah penelitian lapangan, karena peneliti terjun langsung kelapangan di lokasi tempat penelitian dilakukan untuk melihat secara langsun fakta yang terjadi di lapangan, guna mendapatkan informasi yang lebih tepat dan akurat dalam melakukan penelitian sesuai dengan kejadian yang terjadi di lapangan, selain itu juga karena penelitian lapangan adalah salah satu pendekatan luas dalam penelitian kualitatif.

169| Jurnal BASTRA (BahasadanSastra), Vol. 5 No.2, Edisi April 2020/e-ISSN: 25033875 /http:/ojs.ohu.ac.id/index.php/BAS 
Data yang diperolah dari penelitian ini adalah data lisan yakni berupa data ungkapan honorifik yang berasal dari hasil interaksi dan berdasarkan tuturan dari penutur yang ada di lingkungan masyarakat Desa Gunung Sejuk sebagai masyarakat pengguna bahasa Ciacia. Desa Gunung Sejuk menjadi sasaran penelitain karena beberapa faktor sebagai berikut ini.

1. Penuturan bahasa Ciacia di Desa Gunung Sejuk masih tergolong murni dalam arti belum terkontaminasi oleh bahasa daerah lain yang ada di sulawesi tenggara.

2. Mayoritas penutur bahasa Ciacia di Desa Gunung Sejuk berprofesi sebagai petani dan tergolong berpendidikan rendah, hal ini memungkinkan tidak adanya pengaruhpengaruh bahasa indonesia dan bahasa daerah lain terhadap penutur asli bahasa Ciacia.

3. Selain jauh dari ibu kota, Desa Gunung Sejuk merupakan salah satu daerah yang memiliki sistem pemerintahan seperti desa-desa yang lainnya, hal ini mengindikasikan bahwa ada kebudayaan tentang berbahasa sopan dan santun yang masih di pertahankan oleh masyarakat daerah Gunung Sejuk

Sumber data dalam penelitian ini adalah masyarakat yang berada di Desa Gunung Sejuk sebagai penutur asli bahasa Ciacia, Penentuan informan dalam penelitian ini adalah sebagai berikut :
1. Penutur asli bahasa Ciacia yangbermukim di lokasi penelitian

2. Menetap di lokasi penelitian

3. Komunikatif

4. Memiliki artikulasi yang baik.

Nasution (dalam Sugiyono 2013: 306) menyatakan, “dalam penelitian kualitatif, tidak ada pilihan lain selain menjadikan manusia sebagai instrumen penelitian utama, alasannya ialah bahwa, segala sesuatunya belum mempunyai bentuk yang pasti. Masalah, fokus penelitian, prosedur penelitian, hipotesis yang di guanakan, bahkan hasil yang diharapkan, itu semuanya tidak dapat ditentukan secara pasti dan jelas sebelumnya. Segala sesuatu masih perlu di kembangkan dalam penelitian itu. Dalam keadaan yang tidak pasti dan tidak jelas itu, tidak ada pilihan lain dan hanya peneliti itu sendiri sebagai alat satu-satunya yang dapat mencapainya". Selain itu pula peneliti menggunakan tape recorder untuk menjadi instrumen dalam penelitian ini.

Adapaun teknik pengumpulan data dalam penelitian ini sebagai berikut.

1. Teknik Observasi, Teknik pengumpulan data dengan mengadakan pengamatan secara lansung terhadap masyarakat gunung sejuk untuk menemukan bentuk-bentuk honorifik dalam berbahasa yang digunakan oleh masyarakat Desa Gunung Sejuk, dalam teknik observasi ini peneliti menggunakan dua jenis observasi yaitu, observasi bebas dan observasi terencana. 
2. Teknik kerja sama dengan informan teknik memperoleh data dengan bekerja sama dengan informan mengenai bentuk-bentuk ungkapan honorifik dalam berbahasa Ciacia.

3. Teknik simak dan catat,Teknik dengan cara mendengarkan terhadap pemakaian bahasa lisan dalam kehidupan sehari-hari.

4. Rekam, Penulis merekam percakapan yang dijadikan sampel dalam percakapan sehari-hari.

Berikut ini adalah rincian langkahlangkah dalam teknik analisis data yaitu sebagi berikut :

1. Transkripsi data merupakan keseluruhan catatan bentuk data yang telah dirangkum oleh peneliti setelah melakukan observasi berupa ungkapan kesopan santunanatau honorifik dalam bahasa Ciacia pada masyarakat yang ada di Desa Gunung Sejuk.

2. Identifikasi data merupakan tahap di mana peneliti memahami data yang telah dirangkum dalam bentuk catatan untuk diamati dan diperiksa serta dipilih dalam hal ini kaitannya dengan bentuk honorifik.

3. Reduksi data merupakan tahap pengelolahan data yang tersedia mana yang merupakan data verbal (kebahasaan) dan data nonverbal (nonkebahasaan) yang berkaitan dengan bentuk-bentuk honorifik dalam berbahasa Ciacia.
4. Penarikan simpulan, berdasarkan reduksi tentang data di atas maka dapat di deskripsikan tentang bentuk-bentuk honorifik dalam berbahasa Ciacia.

\section{HASIL DAN PEMBAHASAN}

Penelitianini mengenai bentukbentuk ungkapan honorifik dalam berbahasa Ciacia yang digunakan oleh masyarakat Desa Gunung Sejuk. Dengan prinsip yang digunakan oleh. Susilo Supardo (dalam Suhandra 2014: 111) Penggolongan honorifik didasarkan pada dua aspek, yaitu: aspek kebahasaan dan nonkebahasaan. Faktor nonkebahasaan dimaksud adalah konteks yang mempengaruhi pemakaian honorifik tersebut. Penggolongan honorifik berdasarkan aspek kebahasaan dan nonkebahasaan ini menganut atas sosiolinguistik yaitu menempatkan bahasa dalam konteks sosial. Penggolongan honorifik tersebut adalah: honorifik kata kerabat, kata ganti persona, pangkat-jabatan-profesi, gelar religius, tokoh gaib, dan honorifik umum. Dalam masyarakat desa gunung sejuk berdasarkan hasil penelitian tentang honorifik dalam berbahasa Ciacia maka penggunaan honorifik dalam masyarakat Desa Gunung Sejuk dikategorikan dalam honorifik kekerabatan, kata ganti persona, gelar, jabatan dan profesi.

\section{Kesimpulan}

Dari hasil penelitian yang dilakukan mengenai Bentuk-bentuk Honorifik dalam berbahasa Ciacia di desa Gunung Sejuk dengan menggunakan prinsip yang di gunakan oleh supardo (dalam suhandra 2014: 111) Penggolongan honorifik didasarkan pada dua aspek, yaitu: aspek kebahasaan dan nonkebahasaan. Faktor 
nonkebahasaan dimaksud adalah konteks yang mempengaruhi pemakaian honorifik tersebut. Penggolongan honorifik berdasarkan aspek kebahasaan dan nonkebahasaan ini menganut atas sosiolinguistik yaitu menempatkan bahasa dalam konteks sosial. Penggolongan honorifik tersebut adalah: honorifik kata kerabat, kata ganti persona, pangkat-jabatan-profesi, gelar religius, tokoh gaib, dan honorifik umum. Dalam masyarakat Gunung Sejuk terdapat penggunaan bentukbentuk honorifik yang di kategorikan dalam lima jenis honorifik yaitu, honorifik kekerabatan, kata ganti persona, gelar, jabatan dan honorifik profesi.

Penulis berharap penelitian mendatang yang akan dilakukan oleh para peneliti selanjutnya lebih mendalam demi diperoleh hasil yang lebih memuaskan guna menambah keilmuan dalam bidang pragmatik. Penulis menyadari bahwa penelitian ini masih jauh dari penjelasan yang mendalam secara pragmatik, pembelajaran akan terus berproses dan tidak akan berhenti sampai disini, penulis berharap agar penelitian seperti ini masih terus

172| Jurnal BASTRA (BahasadanSastra), Vol. 5 No.2, Edisi April 2020/e-ISSN: 25033875 /http://ojs.ohu.ac.id/index.php/BAS 


\section{DAFTAR PUSTAKA}

Ardianto, Musjiman Rus. 2013.

Pragmatik Direkstif dan

Kesantunan Berbahasa.

Yogyakarta: Gress Publishig.

Arifianti, Erfinda. 2016."Penyimpangan

Maksim Kesopanan Dalam Film La

Mome Karya Olivier Dahlan".

Skripsi. Jurusan Pendidikan Bahasa

Prancis Fakultas Bahasa dan Seni

Universitas Negeri Yogyakarta.

(Http://Eprints.Uny.Ac.Id).Diund uh Pada Tanggal 11 Oktober 2018.

Aslinda, danLeni Syafyahya . 2007.

Pengantar Sosiolinguistik:

Bandung: Refika Aditama.

Chaer, Abdul. 2007. Linguistik Umum. Jakarta: Rineka Cipta.

Chaer, Abdul. 2013. Pengantar Semantik Bahasa Indonesia. Jakarta:Rineka Cipta

Chaer, Abdul Dan Leonie Agustina.

Sosiolinguistik Perkenalan Awal.

Jakarta: Rineka Cipta.

Ningsih,Asti.

2012.

"SistemHonorifikBahasa Korea

PenghormatanTerhadapSubjek

(Subject Honorification),

MitraTutur(Addresee-Related

Honorific), dan Object (Object

Honorification)".

Skripsi.FakultasIlmuPengetahuanB

udaya Program

StudiBahasadanKebudayaan Korea

Depok.(http://lib.ui.ac.id).

DiunduhPadaTanggal 31 Oktober

2018.

Prayitno, Harun Joko. 2017. Studi Sosiopragmatik.

Surakarta:

Universitas Muhamadiyah

Surakarta Press.
Subroto, Edi. 2011. Pengantar Studi Semantik dan Pragmatik. Surakarta: Cakrawala Media.

Suhandra, IkaRahma.

(2014).

SapaandanHonorifik.JurnalJuru

sanPendidikan IPS Ekonomi, 11, 100-115

Sumarsono. 2014. Sosiolinguistik. Yogyakarta: Pustaka Pelajar.

Sugiyono. 2013. Metode Penelitian Pendidikan. Bandung: Alfabet.

Usdiyanto. 2004. Bahasa Militer. Surakarta: Pustaka Cakra.

Yule, George. $2006 . \quad$ Pragmatik. Yogyakarta: Pustaka Pelajar Offest.

173| Jurnal BASTRA (BahasadanSastra), Vol. 5 No.2, Edisi April 2020/e-ISSN: $25033875 /$ http://ojs.ohu.ac.id/index.php/BAS 